\section{Editorial}

\section{OPEN ACCESS}

Received: Dec 28, 2018

Accepted: Jan 10, 2019

Address for Correspondence:

Min Suk Chung, MD, PhD

Department of Anatomy, Ajou University

School of Medicine, 164 World Cup-ro,

Yeongtong-gu, Suwon 16499,

Republic of Korea.

E-mail: dissect@ajou.ac.kr

c 2019 The Korean Academy of Medical

Sciences.

This is an Open Access article distributed under the terms of the Creative Commons Attribution Non-Commercial License (https:// creativecommons.org/licenses/by-nc/4.0/) which permits unrestricted non-commercial use, distribution, and reproduction in any medium, provided the original work is properly cited.

ORCID iDs

Min Suk Chung (DD

https://orcid.org/0000-0002-0527-9763

Disclosure

The author has no potential conflicts of interest to disclose.

\title{
Convergence by Breaking Stereotype
}

\author{
Min Suk Chung $\mathbb{B}$
}

Department of Anatomy, Ajou University School of Medicine, Suwon, Korea

- See the article "New Viewpoint of Surface Anatomy Using the Curved Sectional Planes of a Male Cadaver" in volume 34, e15.

Dro

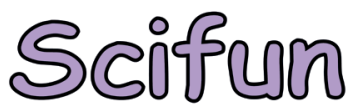

BS Chung, MS Chung (anatomy.co.kr)

Convergence by breaking stereotype

The curved sectional

planes of human 3D model parallel to surface help us understand how deep

the inside structures are.
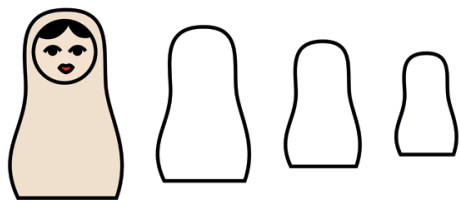

Like the Russian

Matryoshka dolls.

Broken stereotype: Sectional and surface anatomy are independent fields.

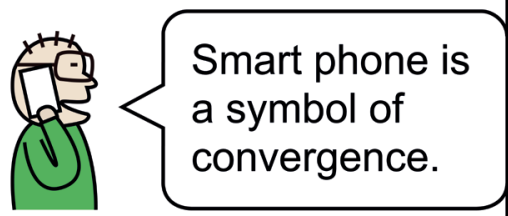

Broken stereotype:

Phone, audio player, camera, computer are independent instruments.
It can be said that sectional anatomy and surface anatomy have converged.

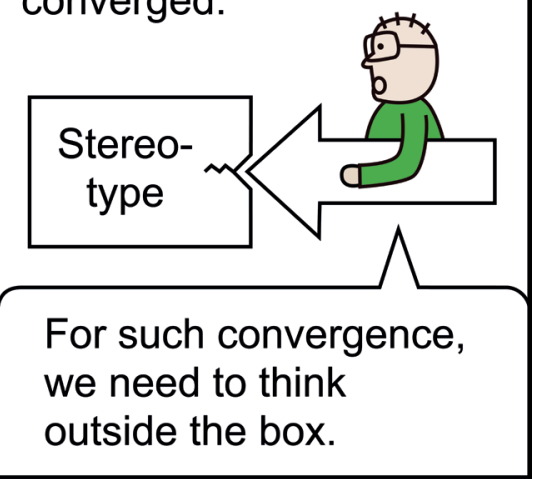

In academic meeting, workshop is the convergence of working and shopping.

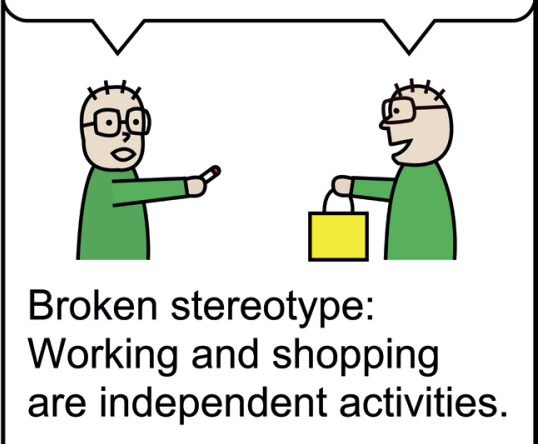

